\title{
DESAFIOS DA EDUCAÇÃO A DISTÂNCIA PARA INCLUSÃO DE USUÁRIOS DEFICIENTES VISUAIS: ANÁLISE HEURÍSTICA DO AMBIENTE VIRTUAL DE APRENDIZAGEM MOODLE
}

\section{CHALLENGES OF DISTANCE EDUCATION FOR INCLUSION OF VISUAL IMPAIRED USERS: HEURISTIC EVALUATION OF THE VIRTUAL LEARNING ENVIRONMENT MOODLE}

\author{
Luis Eduardo Dias Arratia \\ Centro Universitário SENAC \\ luisedu.arratia@gmail.com
}

Análise Heurística, Moodle, Educação a Distância

\begin{abstract}
O presente trabalho apresenta uma análise heurística do ambiente virtual de aprendizagem Moodle, adaptado para usuários deficientes visuais, buscando entender como ambientes virtuais de aprendizagem podem se tornar mais acessíveis para esse público. Para isso, se considera questões de usabilidade e acessibilidade online, e utiliza como método de estudo as heurísticas de Nielsen. São apresentados leitores de telas utilizados por esse público, e guidelines de acessibilidade da W3C. O estudo tem como finalidade a discussão sobre os desafios da Educação a Distância para deficientes visuais.
\end{abstract}

\section{Heuristics Evaluation, Moodle, Distance Education}

This paper presents a heuristic evaluation of the virtual learning environment Moodle, adapted for visually impaired users, seeking to understand how virtual learning environments can become more accessible for this audience. For this, one considers questions of usability and accessibility online, and uses Nielsen heuristics as a study method. Screen readers used by this audience are presented, along with W3C accessibility guidelines. The study aims to discuss the challenges of Distance Education for the visually impaired. 


\section{$16^{\circ}$ \\ ERGODESIGN USIHC CINAHPA}

\section{Introdução}

A Educação a Distância proporciona aos alunos uma maior flexibilidade de horários para estudo, comodidade, economia de tempo e até custos menores, porém ainda não é totalmente acessível e inclusiva para alunos deficientes visuais.

Estudantes com essa característica possuem uma série de problemas para acessar ambientes virtuais de aprendizagem, como por exemplo: problemas de usabilidade, conteúdos que não são acessíveis e aceitação dessa modalidade de ensino por parte destes usuários. (PEREIRA et al, 2014)

De acordo com Censo 2014 da ABED (Associação Brasileira de Educação a Distância), cursos EaD somaram, aproximadamente, quatro milhões de matrículas.

Com o crescimento dessa modalidade, há necessidade de melhorar a acessibilidade de ambientes EaD para pessoas com deficiência visual. Porém, para que isso ocorra, há que se considerar a inclusão social de deficientes visuais e uma Educação Inclusiva.

Tal modalidade, mais do que na educação presencial, necessita de interatividade nas três relações de aprendizagem (aluno-aluno, alunoprofessor e aluno-conteúdo) para redução das percepções de distanciamento por parte dos alunos (TORI, 2010). Dessa forma é importante que as ferramentas de interação sejam inclusivas e que também possibilitem interação entre alunos com e sem deficiência de forma indistinta, a fim de se evitar que deficientes tenham dificuldade de interação.

Para isso, ambientes virtuais de aprendizagem, que possibilitam a interatividade entre as relações de aprendizagem em um curso a distância, devem ser acessíveis e apresentar uma boa usabilidade para alunos deficientes visuais.

Para Silva, Pagliuca e Carvalho (2013) o deficiente visual encontra obstáculos em acessar conteúdos nos ambientes virtuais de aprendizagem. Os autores constataram que usuários deficientes visuais ao utilizarem o ambiente Moodle possuem $16^{\circ}$ Ergodesign - Congresso Internacional de Ergonomia e Usabilidade de Interfaces Humano Tecnológica: Produto, Informações Ambientes Construídos e Transporte

$16^{\circ}$ USIHC - Congresso Internacional de Ergonomia e Usabilidade de Interfaces Humano Computador

CINAHPA | 2017 - Congresso Internacional de Ambientes Hipermídia para Aprendizagem.

dificuldade com materiais em formato PDF, além de encontrarem imagens sem descrição.

O presente artigo apresenta uma análise heurística, baseada em heurísticas de Jakob Nielsen, do ambiente virtual de aprendizagem Moodle.

Assim, se discute desafios para a inclusão de Deficientes Visuais na Educação a Distância considerando acessibilidade e usabilidade de ambientes virtuais de aprendizagem.

\section{Deficiência Visual}

Segundo a $10^{\mathrm{a}}$ Classificação Internacional de Doenças (CID-10), existem quatro níveis de função visual: visão normal, deficiência visual moderada, deficiência visual grave e cegueira. Deficiência visual moderada combinada com deficiência visual grave são agrupadas sob o título "baixa visão". (TALEB et al, 2012)

Pessoas com baixa visão possuem dificuldades em desempenhar tarefas visuais, mesmo com prescrição de lentes corretivas, mas podem aprimorar suas capacidades de realizar tais tarefas com a utilização de estratégias visuais compensatórias. Pessoas cegas ou com visão subnormal apresentam desde a ausência total de visão até alguma percepção luminosa a curta distância que possa indicar formas. De acordo com Taleb et al (2012) "o termo cegueira reúne indivíduos com vários graus de visão residual. Ela não significa, necessariamente, total incapacidade para ver, mas o prejuízo dessa aptidão em níveis incapacitantes para o exercício de tarefas rotineiras".

São utilizados dois componentes da função visual como parâmetro para avaliar a deficiência visual: a acuidade visual (a maior capacidade de discriminar dois pontos a uma determinada distância) e campo visual (a amplitude do espaço percebido pela visão).

\subsection{Leitores de tela para deficientes visuais}

Os leitores de tela são programas que reproduzem, de forma sonora, os eventos ocorridos em um 


\section{$16^{\circ}$ \\ ERGODESIGN USIHC CINAHPA}

computador. Essas interfaces leem para o usuário as informações, botões, e todos os eventos que se apresentam em forma de texto ou equivalente (imagens etiquetadas) na tela do computador. Virtual Vision e Jaws são os leitores de tela mais utilizados no Brasil. (Sonza, 2013 p. 215)

Um exemplo de leitor de tela é o Jaws, criado pela empresa norte-americana Henter-Joyce, se constitui num leitor de telas para o sistema operacional Windows, que verbaliza todos os eventos que ocorrem na interface gráfica do computador. Por meio desse programa, qualquer usuário deficiente visual pode utilizar o computador, através de teclas de atalho específicas.

O Virtual Vision é uma aplicação de síntese de voz, capaz de informar aos usuários quais controles (botão, lista, menu, etc.) estão ativos em determinado momento.

\section{Acessibilidade online para deficientes visuais}

Henry (2005) define Acessibilidade na Web como a possibilidade de percepção, compreensão, navegação e interação de pessoas com algum tipo de deficiência, não somente visual, com a web. Segundo o autor, a acessibilidade para o ambiente digital e informacional beneficia a todas as pessoas e dessa forma, a principal contribuição ao tornar o ambiente acessível para todos é transformar a inclusão de pessoas deficientes em igualdade de oportunidades e de acesso em conteúdos disponibilizado online.

Para Jakob Nielsen (2000), os problemas mais sérios de usabilidade, que ocorrem na World Wide Web estão relacionados a usuários cegos ou com algum tipo de limitação visual.

Com isso em consideração, Santarosa (2004) pontua que a acessibilidade para o deficiente visual envolve diferentes problemas. Entre eles pode-se citar: (1) a acessibilidade ao computador que engloba programas (software) de acesso incluindo diferenciados tipos de ajudas técnicas para usos genéricos de acesso aos computadores e periféricos ou que podem ser especialmente programados para $16^{\circ}$ Ergodesign - Congresso Internacional de Ergonomia e Usabilidade de Interfaces Humano Tecnológica: Produto, Informações Ambientes Construídos e Transporte

$16^{\circ}$ USIHC - Congresso Internacional de Ergonomia e Usabilidade de Interfaces Humano Computador

CINAHPA | 2017 - Congresso Internacional de Ambientes Hipermídia para Aprendizagem.

o acesso à WEB; (2) a acessibilidade ao Navegador; (3) a acessibilidade ao planejamento de páginas WEB, que envolve várias dimensões como conteúdo, estrutura e formato. O elemento fundamental, neste caso, é a escolha da ferramenta de construção de páginas que possa oferecer maiores possibilidades de opções de acessibilidade.

O primeiro e o segundo problema estão relacionados a como os deficientes visuais acessam a internet utilizando o computador ou dispositivo móvel. Para isso, esses usuários utilizam os leitores de tela ou funcionalidades de acessibilidade de seu sistema operacional. O terceiro problema está relacionado à condição de uma página web específica, isto é, de como seus elementos estão sendo disponibilizados e organizados.

Para haver uma padronização das soluções para a acessibilidade do deficiente visual, a W3C, organização internacional que oferece padrões para a Internet, disponibiliza diretrizes para a construção de páginas de web.

A Web Content Accessibility Guidelines, WCAG, 2.0 (Guias de Acessibilidade para Conteúdos Web), fornece uma série de orientações para desenvolvedores que buscam melhorar suas páginas para o público que necessita acessibilidade. A WCAG se baseia em 4 princípios, podendo ser encontrados em sua documentação: Perceptível, Operável, Compreensível e Robusto. O princípio Perceptível visa fornecer alternativas em texto para todo o conteúdo não textual de modo que o mesmo possa ser apresentado de outras formas, de acordo com as necessidades dos usuários, como por exemplo: caracteres ampliados, braille, fala, símbolos ou uma linguagem mais simples. O princípio Operável tem como objetivo fazer com que toda a funcionalidade fique disponível a partir de atalhos no teclado. Já o Compreensível busca tornar o conteúdo textual claro para o usuário. Já o princípio Robusto, procura maximizar a compatibilidade da página com dispositivos de apoio do usuário.

Tais princípios tornariam um ambiente virtual mais acessível para o deficiente visual, porém não é algo presente em páginas de internet. Por exemplo, 


\section{$16^{\circ}$ \\ ERGODESIGN USIHC CINAHPA}

páginas de comércio eletrônico não são acessíveis para deficientes visuais, como descrito por Guimarães e Souza (2015).

\subsection{Usabilidade e Experiência do Usuário}

Usabilidade é definida por Jakob Nielsen como qualidade atribuída para a facilidade de interfaces serem utilizadas, sendo digitais ou não. $\mathrm{O}$ autor descreveu cinco componentes que compõem a usabilidade: Learnability (facilidade de aprendizado), Efficiency (eficiência), Memorability (facilidade de memorização), Errors (prevenção de erros no uso) e Satisfação.

Walter Cybis (2015, p.242), “a usabilidade é a qualidade do uso de um sistema para realização de uma tarefa". O autor demonstra o ISO 9241:11 com os critérios Eficácia, Eficiência e Satisfação. Eficácia é medida pela qualidade e quantidade de objetivos alcançados pelo usuário em uma atividade com o sistema. Eficiência está medida pelo esforço cognitivo e tempo para se realizar alguma tarefa. Satisfação é medida pelo contentamento subjetivo do usuário.

De acordo com Cybis (2004 Apud Norman, 2015), "a Experiência do Usuário explora em maior profundidade as relações estreitas entre usabilidade e beleza, cognição e emoção". A Experiência do Usuário está ligada ao sistema emocional de uma pessoa, e esse sistema emocional interfere na cognição das pessoas, interferindo assim na usabilidade de algum produto. Cybis pontua que uma Experiência de Uso ruim, pode desencadear no usuário emoções como frustração, ansiedade e raiva, fazendo assim com que o usuário não use mais o produto.

Enquanto a acessibilidade está ligada ao acesso de algum usuário em um determinado sistema, a usabilidade mede a facilidade de uso desse sistema. A acessibilidade, somada a uma boa usabilidade, pode proporcionar aos usuários uma boa experiência de uso. $16^{\circ}$ Ergodesign - Congresso Internacional de Ergonomia e Usabilidade de Interfaces Humano Tecnológica: Produto, Informações Ambientes Construídos e Transporte

$16^{\circ}$ USIHC - Congresso Internacional de Ergonomia e Usabilidade de Interfaces Humano Computador

CINAHPA | 2017 - Congresso Internacional de Ambientes Hipermídia para Aprendizagem.

\section{Ambientes Virtuais de Aprendizagem}

A Educação a Distância é uma modalidade educacional para diversas pessoas, em diferentes lugares, através de ambientes que dispõem recursos tecnológicos para auxiliar no processo de ensino e de aprendizagem (SANTINELLO, 2007).

Tais ambientes possuem diversas nominações, tais como: AVA (Ambiente Virtual de Aprendizagem), LMS (Learning Management System), CMS (Course Management System ou Content Management System), LCMS (Learning Content and Management System) e/ou IMS (Instructional Management Systems).

De acordo com Tori (2010, p. 130) são características principais desses ambientes: Gerenciamento do curso (criação de cursos, disciplinas, matrícula de alunos, gerenciamento de senhas, registro de atividades e de acessos realizados pelos usuários, cálculo e publicação de notas, etc.), gerenciamento de conteúdo (armazenamento, gerenciamento, edição e exibição de conteúdo multimídia), disco virtual (área de trabalho, que pode ser individual ou compartilhada, na qual o usuário pode fazer downloads, uploads e visualização de conteúdos), correio eletrônico (para envio e recebimento de mensagens), mensagens instantâneas, fórum de discussão, avaliação (recursos para gerenciamento da aplicação e correção de avaliações) e compartilhamento de recursos. São exemplos de ambientes virtuais de aprendizagem para $\mathrm{EaD}$ : Blackboard, Google Classroom, Moodle e TelEduc.

\subsection{Usabilidade e Experiência do Usuário}

O deficiente visual possui problemas de usabilidade ao acessar Ambientes Virtuais de Aprendizagem, mesmo estes sendo acessíveis. Porém esses problemas não são exclusivos do usuário deficiente visual. O Moodle, por exemplo, para Balbino, Gomes e Santos (2015) não apresenta boa usabilidade, falha em prevenção de erros e não é satisfatório. 


\section{$16^{\circ}$ \\ ERGODESIGN USIHC CINAHPA}

\section{Análise Heurística do Ambiente Virtual de Aprendizagem Moodle}

A Análise Heurística, de Nielsen, 1993, é um método para encontrar os problemas de usabilidade em uma interface. Diferentemente de um teste de usabilidade, onde são necessários um usuário real (participante) e um moderador, a avaliação heurística é feita apenas pelo avaliador que analisa uma determinada interface baseada em princípios definidos.

O ambiente virtual de aprendizagem Moodle foi utilizado como objeto de estudo, e para isso, foi utilizado a demo do sistema disponibilizada online (https://moodle.org/demo/). Desta forma, é possível considerar as características a serem melhoradas na versão básica do Moodle, para as versões adaptadas por cada Universidade.

O acesso ocorreu em 28 de novembro de 2016.

\subsection{Heurísticas utilizadas no estudo}

1. Feedback e visualização do estado do sistema: $\mathrm{O}$ sistema deve informar continuamente ao usuário sobre o que ele está fazendo.

2. Correspondência entre o sistema e o mundo real: A terminologia deve ser baseada na linguagem do usuário e não orientada ao sistema. As informações devem ser organizadas conforme o modelo mental do usuário.

3. Controle fácil para o usuário: $\mathrm{O}$ usuário que controla o sistema pode, a qualquer momento, abortar uma tarefa, ou desfazer uma operação e retornar ao estado anterior.

4. Consistência de padrões: Um mesmo comando ou ação deve ter sempre o mesmo efeito. A mesma operação deve ser apresentada na mesma localização e deve ser formatada/apresentada da mesma maneira para facilitar o reconhecimento.

5. Prevenção de erros: Evitar situações onde os usuários realizem tarefas erradas

6. Minimizar a sobrecarga de memória do usuário: $16^{\circ}$ Ergodesign - Congresso Internacional de Ergonomia e Usabilidade de Interfaces Humano Tecnológica: Produto, Informações Ambientes Construídos e Transporte

$16^{\circ}$ USIHC - Congresso Internacional de Ergonomia e Usabilidade de Interfaces Humano Computador

CINAHPA | 2017 - Congresso Internacional de Ambientes Hipermídia para Aprendizagem.
O sistema deve mostrar os elementos de diálogo e permitir que o usuário faça suas escolhas, sem a necessidade de lembrar um comando específico.

7. Flexibilidade e eficiência de uso: Para usuários experientes executarem as operações mais rapidamente. Atalhos também servem para recuperar informações que estão numa profundidade na árvore navegacional a partir da interface principal.

8. Diálogos simples e naturais: Deve-se apresentar exatamente a informação que o usuário precisa no momento. A sequência da interação e o acesso aos objetos e operações devem ser compatíveis com o modo pelo qual o usuário realiza suas tarefas.

9. Boas mensagens de erro: Linguagem clara e sem códigos, as mensagens de erro não devem culpar ou intimidar o usuário quando o sistema apresentar algum problema.

10. Documentação para auxílio: A documentação do sistema com atalhos e funcionalidades deve estar disponível para o usuário.

\subsection{Adaptação de análise do Moodle para deficientes visuais}

Para um usuário cego ou com baixa visão, é importante considerar, com as heurísticas listadas anteriormente, elementos da interface de maneira não visual. Para isso, é necessário mapear as diferentes maneiras de interação e como estas ocorrem.

Para realização da avaliação, foi utilizado o Software NVDA, para simular a navegação de um usuário deficiente visual. O NVDA é um leitor de telas que possui comandos para auxiliar os usuários na utilização do computador. Os principais comandos ocorrem pelas teclas "TAB", "1", "2" e "3" e setas. Em uma página web, a tecla "TAB" é utilizada para o leitor ir para o próximo elemento. As teclas numéricas são utilizadas para o leitor passar pelos elementos semânticos (código) das páginas. Por exemplo, quando o usuário aperta a tela 1, o leitor de tela lê o próximo elemento que possui uma tag $\mathrm{html}\langle\mathrm{h} 1\rangle$.
Realização:

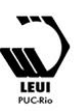




\section{$16^{\circ}$ \\ ERGODESIGN USIHC CINAHPA}

A navegação ocorreu na demo do Moodle, disponibilizado no site oficial do LMS, no modo aluno.

\subsection{Análise}

Seguindo a adaptação das heurísticas, foi possível perceber algumas características na interface do Moodle que precisam ser melhoradas para usuários deficientes visuais.

1. Feedbacks: O usuário consegue saber o que está fazendo pelo feedback sonoro do leitor de telas. Porém, há imagens que não possuem descrição no código, fazendo com que o usuário não tenha uma percepção total de todos os elementos da interface.

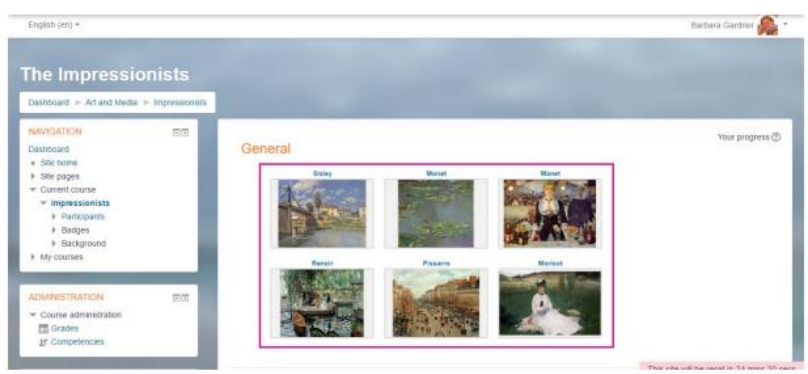

Figura 1 - Imagens no AVA Moodle

Imagens sem descrição: É possível saber que há uma imagem ali, porém não há nenhuma tag no código de descreva a imagem para o leitor de telas.

2. Correspondência entre o sistema e o mundo real: Como todos os feedbacks da interface ocorrem por meio do leitor de tela, não há nenhuma metáfora nas páginas do Moodle que ajudem o usuário a entender como realizar alguma ação dentro do sistema.

\section{Controle: A interface do Moodle possui} controles simples para usuários videntes (como o breadcrumb), porém é algo de difícil acesso para deficientes visuais. Também não há nenhum tipo de "desfazer ação", tanto para usuários videntes, quanto para cegos. Isso faz com que os usuários não tenham controle mais avançados do sistema. $16^{\circ}$ Ergodesign - Congresso Internacional de Ergonomia e Usabilidade de Interfaces Humano Tecnológica: Produto, Informações Ambientes Construídos e Transporte

$16^{\circ}$ USIHC - Congresso Internacional de Ergonomia e Usabilidade de Interfaces Humano Computador

CINAHPA | 2017 - Congresso Internacional de Ambientes Hipermídia para Aprendizagem.

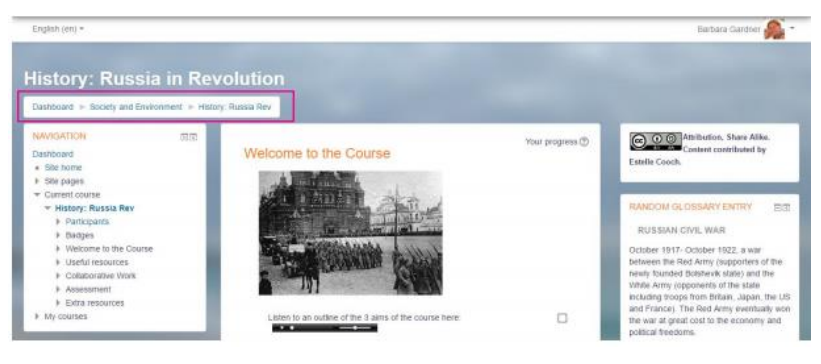

Figura 2 - Breadcrumbs em uma página de aula no Moodle

Breadcrumb: elemento de navegação para os usuários confuso se obtido pelo leitor de telas.

4. Consistência de Padrões: O Moodle possui páginas similares, o que facilita a navegação conforme o usuário se acostuma com a interface.

5. Sobrecarga do Usuário: Usuários cegos teriam dificuldade para entender a interface do Moodle. Para isso, é necessário navegar por toda a página com o leitor de telas. Também não há nenhum tipo de comando específico para o usuário ir diretamente para uma seção desejada.

6. Flexibilidade: Como a navegação ocorre por meio do leitor de telas, mesmo usuários experientes devem repetir sempre os mesmos processos para realizar as tarefas desejadas. Atalhos seriam necessários para usuários deficientes visuais terem maior flexibilidade de navegação.

7. Mensagem de erro: Como foi utilizada a versão demo do Moodle, não foi possível realizar estudos sobre essa heurística.

8. Diálogos naturais: O Moodle não apresenta diálogos naturais para usuários deficientes visuais. Percebe-se isso em funcionalidades onde não há como o leitor de telas traduzir a informação para o usuário, ou funções que são necessárias a utilização do mouse, como calendário e customização da interface, por exemplo. 


\section{$16^{\circ}$ \\ ERGODESIGN USIHC CINAHPA}

$16^{\circ}$ Ergodesign - Congresso Internacional de Ergonomia e Usabilidade de Interfaces Humano Tecnológica: Produto, Informações Ambientes Construídos e Transporte

$16^{\circ}$ USIHC - Congresso Internacional de Ergonomia e Usabilidade de Interfaces Humano Computador

CINAHPA | 2017 - Congresso Internacional de Ambientes Hipermídia para Aprendizagem.

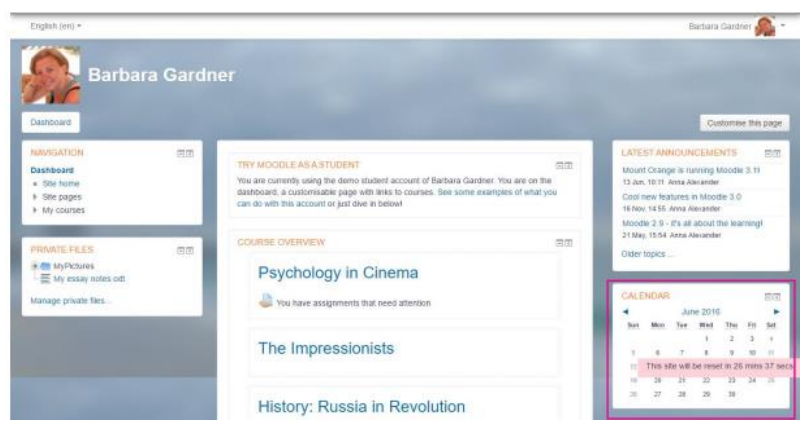

Figura 3 - Calendário padrão do Moodle

Calendário: Inacessível para o leitor de telas e é necessário a utilização do mouse.

\section{Documentação: Não há na interface Demo do} Moodle alguma documentação ou coachmark que auxilie o usuário a aprender a utilizar o sistema.

Para usuários deficientes visuais, seria necessário que houvesse uma documentação das

funcionalidades e dos caminhos para se chegar a essas funcionalidades. Assim, um usuário cego, por exemplo, não precisaria mapear toda a página com o leitor de tela para conseguir encontrar o conteúdo e informação que desejar.

\subsection{Resultados}

O ambiente virtual de aprendizagem Moodle não é totalmente acessível para usuários deficientes visuais, mas é possível a utilização por esses usuários. Com um tempo de aprendizagem, usuários com esse perfil conseguirão utilizar o sistema, mesmo com alguns problemas de usabilidade.

É importante ressaltar que, para uma análise mais concreta, seria necessário um estudo com usuários reais nesse ambiente. A avaliação heurística pode ser utilizada como uma base para possíveis testes de usabilidade, uma vez que as características a serem melhoras na interface do Moodle estão levantadas.

\section{Considerações Finais}

A educação a distância oferece uma série de benefícios para usuários deficientes visuais, porém ainda não é totalmente acessível para esse público. Dentre os motivos para essa falta de acessibilidade, pode-se destacar os ambientes virtuais de aprendizagem, pelos quais os usuários deficientes visuais utilizariam essa modalidade, que não apresentam uma boa usabilidade em suas interfaces.

O ambiente virtual de aprendizagem Moodle, por exemplo, possui características que dificultam a navegação de usuários deficientes visuais, especialmente os que utilizam leitores de tela para interação.

É importante ressaltar que a experiência de uso por usuários deficientes visuais é apenas um dos desafios para que a modalidade seja mais inclusiva e acessível para tal público.

Também é necessário considerar questões pedagógicas e relacionadas a Design Instrucional, como ocorre o aprendizado por estudantes cegos e com baixa visão, inclusão social, entre diversos fatores que influenciam a educação.

\section{BIBLIOGRAFIA}

Balbino, L; Gomes, D; Santos, G. A Uabilidade de um AVA: Um estudo sobre o Moodle IFRN CAMPUS CURRAIS NOVOS. 2015.

Disponívem em:

<http://www2.ifrn.edu.br/ojs/index.php/HOLOS/ar ticle/view/2957> Acesso em 15/12/2016

CYBIS, Walter. Ergonomia e Usabilidade: Conceitos, Métodos e Aplicações. 3. ed. São Paulo: Novatec, 2015.

GUIMARÃES, I; SOUZA, M. Acessibilidade em websites de comércio eletrônico: avaliação através da interação com usuários cegos na Paraíba. 2015 Disponívem em:

<http://periodicos.ufpb.br/ojs/index.php/pbcib/artic le/view/24559/13438> Acesso em: 14/12/2016

HENRY, Shawn Lawton; Education and

Outreach Working Group (EOWG).

Introduction to Web Accessibility. World Wide
Realização:

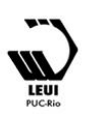




\section{$16^{\circ}$ \\ ERGODESIGN USIHC CINAHPA}

$16^{\circ}$ Ergodesign - Congresso Internacional de Ergonomia e Usabilidade de Interfaces Humano Tecnológica: Produto, Informações Ambientes Construídos e Transporte

$16^{\circ}$ USIHC - Congresso Internacional de Ergonomia e Usabilidade de Interfaces Humano Computador

CINAHPA | 2017 - Congresso Internacional de Ambientes Hipermídia para Aprendizagem.

Web Consortium/Web Accessibility Initiative (W3C/WAI). 2005. Disponível em:<

https://www.w3.org/WAI/intro/accessibility.php>. Acesso em 15/12/2016.

NIELSEN, J. Engireering of Usability

[Engenharia da Usabilidade]. Boston, Academic Press, 1993.

PEREIRA et al. A Inclusão de Pessoas com deficiência visual na EAD segundo a ótica do aluno e da equipe multidisciplinar. 2014 Disponível em: < http://esud2014.nute.ufsc.br/anaisesud2014/files/pdf/126681.pdf> Acesso em: $15 / 12 / 2016$

TORI, R. Educação em Distância. São Paulo: Editora Senac, 2010.

SANTAROSA, Lucila. Ambientes Virtuais Acessíveis sob a perspectiva de usuários deficientes visuais. 2008 .

Disponível em:

<https://www.researchgate.net/publication/267809 230_Ambientes_Virtuais_Acessiveis_sob_a_persp ectiva_de_usuarios_deficientes_visuais> Acesso em: $14 / 12 / 2016$

SILVA, A; PAGLIUCA, L; CARVALHO, A. Acessibilidade no ambiente virtual de aprendizagem moodle: revisão de literatura. 2013. Disponível em:

$<$ https://periodicos.ufpe.br/revistas/revistaenferma gem/article/view/11563> Acesso em: 14/12/2016

SONZA, Andréa. Acessibilidade de Deficientes Visuais aos Ambientes Digitais. 2004.

Disponível em:

<http://www.lume.ufrgs.br/bitstream/handle/10183 15626/000428874.pdf? sequence $=1>$ Acesso em: $15 / 12 / 2016$

TALEB, Alexandre; FARIA, Marco Antonio Rey de; ÁVILA, Marcos. As condições da saúde ocular no Brasil. São Paulo: Conselho Brasileiro de Oftalmologia, 2012 